\title{
Identification of the tolerant capacity to aquatic environment factors (temperature, pH and dissolved oxygen) of Asian bumblebee catfish (Pseudomystus siamensis Regan, 1913)
}

\author{
Binh T. T. Vo*, Chau M. Pham, Truc T. T. Nguyen, Tuan V. Vo, \& Tu V. Nguyen \\ Faculty of Fisheries, Nong Lam University, Ho Chi Minh City, Vietnam
}

ARTICLE INFO
Research Paper
Received: May 07, 2019
Revised: September 09, 2019
Accepted: September 24, 2019
Keywords
Asian bumblebee catfish
Dissolved oxygen
pH, temperature
Tolerant capacity
*Corresponding author
Vo Thi Thanh Binh
Email: vtbinh1975@yahoo.com

Cited as: Vo, B. T. T., Pham, C. M., Nguyen, T. T. T., Vo, T. V., \& Nguyen, T. V. (2019). Identification of the tolerant capacity to aquatic environment factors (temperature, $\mathrm{pH}$ and dissolved oxygen) of Asian bumblebee catfish (Pseudomystus siamensis Regan, 1913). The Journal of Agriculture and Development 18(5), 43-51. 


\title{
Xác định khả năng chịu đựng một số yếu tố môi trường nước (nhiệt độ, $\mathrm{pH}$ và ôxy hòa tan) của cá chốt bông (Pseudomystus siamensis Regan, 1913)
}

\author{
Võ Thị Thanh Bình*, Phạm Minh Châu, Nguyễn Thị Thanh Trúc, \\ Võ Văn Tuấn \& Nguyễn Văn Tư
}

Khoa Thủy Sản, Trường Đại Học Nông Lâm TP.HCM, TP. Hồ Chí Minh

\section{THÔNG TIN BÀI BÁO}

\section{Bài báo khoa học}

Ngày nhận: 07/05/2019

Ngày chỉnh sửa: 09/09/2019

Ngày chấp nhận: 24/09/2019

Từ khóa

Cá chốt bông

Khả năng chịu dựng

Nhiệt độ

Ôxy hòa tan

$\mathrm{pH}$

*Tác giả liên hệ

Võ Thị Thanh Bình

Email: vtbinh1975@yahoo.com

\section{TÓM TẮT}

Cá chốt bông (Pseudomystus siamensis) thuộc họ cá ngạnh Bagridae và là loài cá cảnh có giá trị kinh tế. Tuy nhiên cho đến nay các công bố về đặc điểm sinh học của loài cá này còn rất hạn chế. Nghiên cứu về khả năng chịu đựng một số yếu tố môi trường nước (nhiệt độ, $\mathrm{pH}$ và ôxy hòa tan) của cá chốt bông ở các giai đoạn phôi, cá mới nở và cá 10 ngày tuổi đã được thực hiện từ tháng 7/2018 đến tháng 1/2019 tại Khoa Thủy Sản - Trường Đại học Nông Lâm TP.HCM. Các kết quả nghiên cứu cho thấy ngưỡng nhiệt độ cao và thấp của phôi là $32,5^{\circ} \mathrm{C}$ và $22,3^{\circ} \mathrm{C}$; cá mới nở là $36,7^{\circ} \mathrm{C}$ và $18,7^{\circ} \mathrm{C}$; cá 10 ngày tuổi là $38,6^{\circ} \mathrm{C}$ và $15,9^{\circ} \mathrm{C}$. Ngưỡng $\mathrm{pH}$ cao và thấp ở giai đoạn phôi là 10,7 và 4,4 ; cá mới nở là 10,2 và 3,7 ; cá 10 ngày tuổi là 10,2 và 3,8 . Ngưỡng ôxy của cá chốt bông giai đoạn phôi, cá mới nở và cá 10 ngày tuổi lần lượt là 4,7 ; 1,$1 ; 1,0 \mathrm{mg} \mathrm{O} \mathrm{O}_{2} / \mathrm{L}$. Cá chốt bông giai đoạn sau nở chịu đựng những yếu tố bất lợi của môi trường tốt hơn giai đoạn phôi. Kết quả nghiên cứu là cơ sở khoa học quan trọng cho các nghiên cứu về sản xuất giống và bảo tồn loài cá này trong tương lai.

\section{1. Đắt Vấn Đề}

Cá chốt bông (Pseudomystus siamensis Regan, 1913) thuộc giống cá chốt Pseudomystus, họ cá ngạnh Bagridae. Bagridae là một trong những họ lớn với các thành viên có thể tìm thấy khắp châu Á, châu Phi và Trung Đông. Ở châu Á, cá chốt bông phân bố ở lưu vực các sông Mekong và Chao Phraya, và bán đảo Thái Lan. Nhóm cá ngạnh này được quan tâm đặc biệt do có nhiều loài cá có giá trị làm cá cảnh so với các họ cá da trơn (catfish) châu Á khác. Ngày nay, phần lớn các loài dùng làm cá cảnh thuộc giống $P s e u-$ domystus do chúng sở hữu sự đa dạng về màu sắc, có các màu tương phản nổi bật với các dãy hoặc vệt màu tương phản nằm trên thân và vây. Trong số các loài cá cảnh thuộc giống Pseudomystus thì cá chốt bông được ưa chuộng hơn cả và được xuất/nhập khẩu với tên gọi 'bumblebee catfish' (Linder, 2000a \& b). Tuy nhiên, loài cá này chỉ được khai thác từ tự nhiên nên số lượng có giới hạn. Ngày nay, nhu cầu tiêu thụ nguồn cá này cho mục đích chơi cảnh tương đối cao dẫn tới việc khai thác quá mức loài cá này ngoài tự nhiên.

Ở Việt Nam, cá chốt bông được người dân khai thác nhiều ở vùng Tân Châu, Thoại Sơn (An Giang) và hồ Trị An (Trảng Bom - Đồng Nai). Theo kinh nghiệm của người dân thì cá chốt bông ở các địa phương này thường bắt gặp vào đầu mùa mưa và được đánh bắt, khai thác chủ yếu vào các tháng 10, 11 hằng năm (Vo, 2015).

Ngoài nghiên cứu định loại (Vo, 2015), cho đến nay có rất ít nghiên cứu về đặc điểm sinh học trên loài cá này. Vì vậy, việc tiến hành nghiên cứu xác định khả năng chịu đựng các yếu tố môi trường chính (nhiệt độ, pH, ôxy hòa tan) của cá chốt bông là hết sức cần thiết để làm cơ sở khoa học việc thuần dưỡng, sản xuất giống, phát triển nuôi và bảo vệ nguồn lợi tự nhiên đối tượng này 
trong tương lai.

\section{Vật Liệu và Phương Pháp Nghiên Cứu}

Nghiên cứu được tiến hành từ tháng 7/2018 đến tháng 1/2019 tại Trại thực nghiệm Khoa Thủy Sản, Trường Đại học Nông Lâm TP.HCM.

Cá chốt bông bố mẹ được tuyển chọn từ đàn cá chốt bông tự nhiên thu từ các tỉnh miền Tây và Đông Nam Bộ. Cá bố mẹ được nuôi vỗ trong ao lót bạt và được kích thích sinh sản với HCG. Cá sau khi nở được ương nuôi với thức ăn là Moina và trùn chỉ Limnodrilus hoffmeistery.

\subsection{Thí nghiệm xác định ngưỡng nhiệt độ của cá chốt bông}

Thí nghiệm xác định nhiệt độ bắt đầu gây chết (incipient lethal temperature, ILT) - nhiệt độ gây chết $50 \%$ đối tượng thí nghiệm khi được xử lý với một loạt các nhiệt độ tăng hay giảm ở khoảng thời gian 24 giờ (Beitinger \& ctv., 2000) - được bố trí theo kiểu hoàn toàn ngẫu nhiên với 3 lần lặp lại. Đối tượng nghiên cứu (phôi đã phát triển xa hơn giai đoạn phôi vị, cá mới nở và cá 10 ngày tuổi) được chứa trong các bình nhựa có 2 lít nước với mật độ 20 mẫu/bình. Các bình thí nghiệm được đặt trong một thùng xốp có chứa nước. Dùng nước nóng (xác định nhiệt độ cao gây chết (IU(pper)LT)) hay nước lạnh (xác định nhiệt độ thấp gây chết (IL(ower)LT)) thêm vào nước trong thùng xốp để gián tiếp tăng hay giảm nhiệt độ nước của bình chứa mẫu vật với mức $1^{0} \mathrm{C}$ ở mỗi lần tăng hay giảm. Đặt nhiệt kế trong bình thí nghiệm để theo dõi nhiệt độ và đảm bảo nhiệt độ trong bình tăng hay giảm không quá $0,2^{0} \mathrm{C} /$ giờ. Sau khi đạt nhiệt độ mong muốn, nhiệt độ trong bình được giữ ổn định và ghi nhận số mẫu vật bị chết liên tục trong 24 giờ. Biểu hiện của phôi chết là sự biến đổi màu và trở nên mờ đục, của cá mới nở là sự ngừng vận động và của cá 10 ngày tuổi là sự ngừng cử động của nắp mang.

\subsection{Thí nghiệm xác định ngưỡng $\mathrm{pH}$ của cá chốt bông}

Thí nghiệm xác định $\mathrm{pH}$ bắt đầu gây chết (incipient lethal pH, ILpH) - pH gây chết $50 \%$ đối tượng thí nghiệm khi được xử lý với một loạt các $\mathrm{pH}$ tăng hay giảm ở khoảng thời gian 24 giờ cũng được bố trí theo kiểu hoàn toàn ngẫu nhiên với 3 lần lặp lại. Đối tượng nghiên cứu được chứa trong các bình nhựa có 2 lít nước với mật độ 20 mẫu/bình. Điều chỉnh $\mathrm{pH}$ nước trong bình thí nghiệm với dung dịch $\mathrm{NaOH} 0,1 \mathrm{~N}$ dể tăng $\mathrm{pH}$ (xác định $\mathrm{pH}$ cao gây chết (IU(pper)LpH)) và $\mathrm{H}_{2} \mathrm{SO}_{4} 0,1 \mathrm{~N}$ để giảm $\mathrm{pH}$ (xác định $\mathrm{pH}$ thấp gây chết (IL(ower) $\mathrm{LpH})$ ) dể có giá trị pH theo yêu cầu với mức 1 giá trị $\mathrm{pH}$ ở mỗi lần tăng hay giảm. Sau khi đạt pH mong muốn, $\mathrm{pH}$ trong bình được giữ ổn định và ghi nhận số mẫu vật bị chết liên tục trong 24 giờ.

Trong cả 2 thí nghiệm trên, các bình được sục khí nhẹ để đảm bảo ôxy hòa tan đầy đủ. Các mẫu vật chết được vớt bỏ ngay để tránh ảnh hưởng xấu đến chất lượng nước trong bình. Nhiệt độ hay $\mathrm{pH}$ cao và thấp gây chết mẫu vật được tính toán dựa trên phân tích hồi qui tuyến tính của tỷ lệ chết ở 24 giờ theo nhiệt độ hay $\mathrm{pH}$.

\subsection{Thí nghiệm xác định ngưỡng ôxy của cá chốt bông}

Ngưỡng ôxy của cá được xác định bằng phương pháp bình kín (Wokoma \& Marioghae, 1996). Cho nước vào đầy bình thủy tinh $500 \mathrm{~mL}$, thả mẫu mật độ 20 con nhẹ nhàng vào bình và đậy nắp thật kín (tránh không có bọt khí). Tiếp tục theo dõi đến khi nào $>50 \%$ phôi trở nên mờ đục hay cá không còn hoạt động nữa thì lấy ra một mẫu nước để xác định ôxy hòa tan - được xem như ngưỡng ôxy của phôi hay cá (Nguyen, 2005).

Nhiệt độ được đo với nhiệt kế thủy ngân $(0$ $\left.50^{\circ} \mathrm{C}\right), \mathrm{pH}$ được do với $\mathrm{pH}$ meter hiệu HANNA và ôxy hòa tan được xác định với phương pháp chuẩn độ kiềm Winkler.

\subsection{Xử lý số liệu}

Tất cả số liệu về tỷ lệ chết được chuyển đổi thành $\arcsin \sqrt{ }$ và được phân tích ANOVA một yếu tố (One-way ANOVA) với phép thử DUCAN bằng phần mềm SPSS. Phân tích hồi qui tuyến tính của tỷ lệ chết (được chuyển đổi thành probit) ở 24 giờ theo nhiệt độ hay $\mathrm{pH}$ (được chuyển đổi thành Log10) sử dụng phần mềm Excel.

\section{Kết Quả và Thảo Luận}

\subsection{Ngưỡng nhiệt độ của cá chốt bông}

\subsubsection{Giai đoạn phôi}

- Ngưỡng nhiệt độ cao gây chết (IULT)

Phôi không chết ở các nhiệt độ 30 và $31^{0} \mathrm{C}$. Hiện tượng phôi chết xảy ra ở các nghiệm thức 
có giá trị nhiệt độ từ $32-39^{\circ} \mathrm{C}$. Tỷ lệ phôi chết tích lũy ở 24 giờ ở nghiệm thức $32^{0} \mathrm{C}$ là $38,3 \%$, tăng lên $90 \%$ ở $33^{\circ} \mathrm{C}$ và ở các nhiệt độ cao hơn $\left(34-39^{0} \mathrm{C}\right)$ có tỷ lệ phôi chết $100 \%$ sau 1 giờ thí nghiệm. Tỷ lệ phôi chết tích lũy ở 24 giờ ở $33^{0} \mathrm{C}$ là khác biệt có ý nghĩa thống kê $(P<0,05)$ so với tỷ lệ chết ở các nhiệt độ khác.

Phương trình hồi qui tuyến tính của tỷ lệ phôi chết $(\mathrm{y})$ theo nhiệt độ cao $(\mathrm{x})$ là $\mathrm{y}=207,91 \mathrm{x}-$ 309,36 ( $\left.\mathrm{R}^{2}=0,9535\right)$. Như vậy, trong thí nghiệm này, nhiệt độ cao gây chết (IULT) cá chốt bông giai đoạn phôi được xác định là $32,5^{0} \mathrm{C}$ (Hình 1$)$.

\section{- Ngưỡng nhiệt độ thấp gây chết (ILLT)}

Tương tự như ở thí nghiệm nhiệt độ cao, phôi không chết ở các nhiệt độ từ $26-24^{0} \mathrm{C}$. Hiện tượng phôi chết xảy ra ở các nghiệm thức có giá trị nhiệt độ từ $23,5-14^{\circ} \mathrm{C}$. Tỷ lệ phôi chết tích lũy ở 24 giờ ở nghiệm thức $23,5^{0} \mathrm{C}$ là $56,6 \%$, tăng lên $68,3 \%$ ở $23^{\circ} \mathrm{C}, 75 \%$ ơ $21^{\circ} \mathrm{C}$ và $76,6 \%$ ơ $22^{\circ} \mathrm{C}$; còn ở các nhiệt độ thấp hơn $\left(20-14^{0} \mathrm{C}\right)$, tỷ lệ phôi chết là $100 \%$ sau 1 giờ thí nghiệm. Tỷ lệ phôi chết tích lũy ở 24 giờ ở 21 và $22^{\circ} \mathrm{C}$ là khác biệt không có ý nghĩa thống kê $(P>0,05)$ nhưng khác biệt có ý nghĩa thống kê $(P<0,05)$ so với tỷ lệ chết ở các nhiệt độ khác.

Phương trình hồi qui tuyến tính của tỷ lệ phôi chết $(\mathrm{y})$ theo nhiệt độ thấp $(\mathrm{x})$ là $\mathrm{y}=-74,411 \mathrm{x}$ $+105,32\left(\mathrm{R}^{2}=0,6435\right)$. Trong thí nghiệm này, nhiệt độ thấp gây chết (ILLT) cá chốt bông giai đoạn phôi được xác định là $22,3^{\circ} \mathrm{C}$ (Hình 1$)$.

\subsubsection{Giai đoạn cá mới nở}

- Ngưỡng nhiệt độ cao gây chết (IULT)

Cá không chết ở các nhiệt độ từ $30-34^{0} \mathrm{C}$. Hiện tượng cá chết xảy ra ở các nghiệm thức có giá trị nhiệt độ từ $35-39^{0} \mathrm{C}$. Tỷ lệ cá chết tích lũy ở 24 giờ ở nghiệm thức $35^{\circ} \mathrm{C}$ là $21,6 \%$, tăng lên $55 \%$ ở nhiệt độ $37^{\circ} \mathrm{C}$ và $71,6 \%$ ở nhiệt độ $38^{\circ} \mathrm{C}$; ở nhiệt độ cao hơn $\left(39^{\circ} \mathrm{C}\right)$, tỷ lệ cá chết là $100 \%$ sau 1 giờ thí nghiệm. Tỷ lệ cá chết tích lũy ở 24 giờ ở các nhiệt độ $35-38^{\circ} \mathrm{C}$ là khác biệt có ý nghĩa thống kê $(P<0,05)$ và cũng khác biệt so với tỷ lệ chết ở các nhiệt độ khác.

Phương trình hồi qui tuyến tính của tỷ lệ cá chết $(\mathrm{y})$ theo nhiệt độ cao $(\mathrm{x})$ là $\mathrm{y}=117,19 \mathrm{x}-$ $178,42\left(\mathrm{R}^{2}=0,8552\right)$. Như vậy trong thí nghiệm này, nhiệt độ cao gây chết (IULT) cá chốt bông giai đoạn mới nở được xác định là $36,7^{\circ} \mathrm{C}$ (Hình 2).

- Ngưỡng nhiệt độ thấp gây chết (ILLT)
Cá không chết ở các nhiệt độ từ $26-21^{0} \mathrm{C}$. Hiện tượng cá chết xảy ra ở các nghiệm thức có giá trị nhiệt độ từ $20-14^{0} \mathrm{C}$. Tỷ lệ cá chết tích lũy ở 24 giờ ở nghiệm thức $20^{\circ} \mathrm{C}$ là $13,3 \%$, tăng lên $53,3 \%$ ở $19^{\circ} \mathrm{C}$ và $60,0 \%$ ở $18^{\circ} \mathrm{C}$; còn ở các nhiệt độ thấp hơn $\left(17-14^{0} \mathrm{C}\right)$, tỷ lệ cá chết là $100 \%$ sau 1 giờ thí nghiệm. Tỷ lệ cá chết tích lũy ở 24 giờ ở các nhiệt độ $20-18^{\circ} \mathrm{C}$ là khác biệt có ý nghĩa thống kê $(P<0,05)$ và cũng khác biệt so với tỷ lệ chết ở các nhiệt độ khác.

Phương trình hồi qui tuyến tính của tỷ lệ cá chết $(\mathrm{y})$ theo nhiệt độ thấp $(\mathrm{x})$ là $\mathrm{y}=-81,739 \mathrm{x}$ $+109,01\left(\mathrm{R}^{2}=0,8949\right)$. Trong thí nghiệm này, nhiệt độ thấp gây chết (ILLT) cá chốt bông giai đoạn mới nở được xác định là $18,7^{0} \mathrm{C}$ (Hình 2).

\subsubsection{Giai đoạn cá 10 ngày tuổi}

- Ngưỡng nhiệt độ cao gây chết (IULT)

Cá không chết ở các nhiệt độ từ $30-37^{0} \mathrm{C}$. Hiện tượng cá chết xảy ra ở các nghiệm thức có giá trị nhiệt độ từ $38-39^{0} \mathrm{C}$. Tỷ lệ cá chết tích lũy ở 24 giờ ở nghiệm thức $38^{\circ} \mathrm{C}$ là $46,6 \%$ và tăng lên $55,0 \%$ ở nhiệt độ $39^{\circ} \mathrm{C}$. Tỷ lệ cá chết tích lũy ở 24 giờ ở 38 và $39^{\circ} \mathrm{C}$ là khác biệt có ý nghĩa thống kê $(P<0,05)$ và cũng khác biệt so với tỷ lệ chết ở các nhiệt độ khác.

Phương trình hồi qui tuyến tính của tỷ lệ cá chêt $(\mathrm{y})$ theo nhiệt độ cao $(\mathrm{x})$ là $\mathrm{y}=225,08 \mathrm{x}$ - 352,21 $\left(\mathrm{R}^{2}=0,7871\right)$. Nhiệt độ cao gây chết (IULT) cá chốt bông giai đoạn 10 ngày tuổi được xác định là $38,6^{\circ} \mathrm{C}$ (Hình 3 ).

- Ngưỡng nhiệt độ thấp gây chết (ILLT)

Cá không chết ở các nhiệt độ từ $26-18^{\circ} \mathrm{C}$. Hiện tượng cá chết xảy ra ở các nghiệm thức có giá trị nhiệt độ từ $17-14^{0} \mathrm{C}$; trong đó, ở nhiệt độ $14^{0} \mathrm{C}$ tỷ lệ cá chết là $100 \%$ sau 1 giờ thí nghiệm. Ở các nghiệm thức 17,16 và $15^{\circ} \mathrm{C}$, tỷ lệ cá chết tích lũy sau 24 giờ là tương đương nhau và khác biệt có ý nghĩa thống kê so với các nghiệm thức còn lại $(P<0,05)$.

Phương trình hồi qui tuyến tính của tỷ lệ cá chết $(\mathrm{y})$ theo nhiệt độ thấp $(\mathrm{x})$ là $\mathrm{y}=-63,332 \mathrm{x}$ $+81,073\left(\mathrm{R}^{2}=0,7643\right)$. Nhiệt độ thấp gây chêt (ILLT) cá chốt bông giai đoạn 10 ngày tuổi được xác định là $15,9^{\circ} \mathrm{C}$ (Hình 3 ).

Hầu hết các loài cá nuôi phân bố tự nhiên ở Đồng bằng sông Cửu Long (ĐBSCL) và những vùng phân bố có vĩ độ thấp thì nhiệt độ thích hợp cho phôi phát triển từ $27-31^{\circ} \mathrm{C}$ (Pham \& Nguyen, 2009). Trong suốt quá trình phát triển 

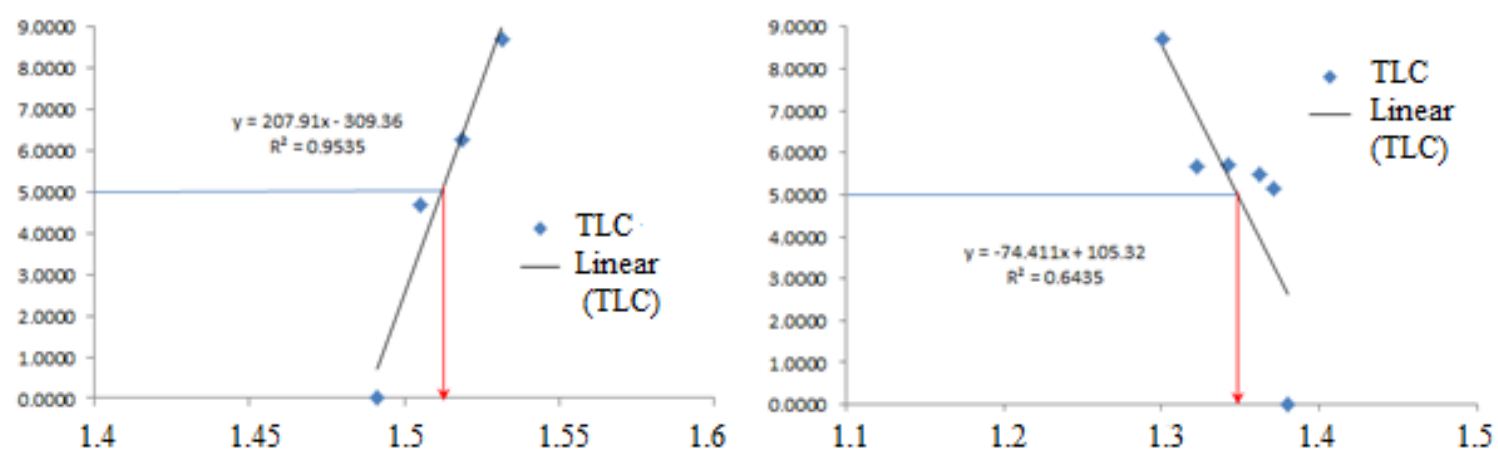

Hình 1. Phương trình hồi qui tuyến tính của tỷ lệ chết phôi cá chốt bông theo nhiệt độ cao (trái) và thấp (phải)
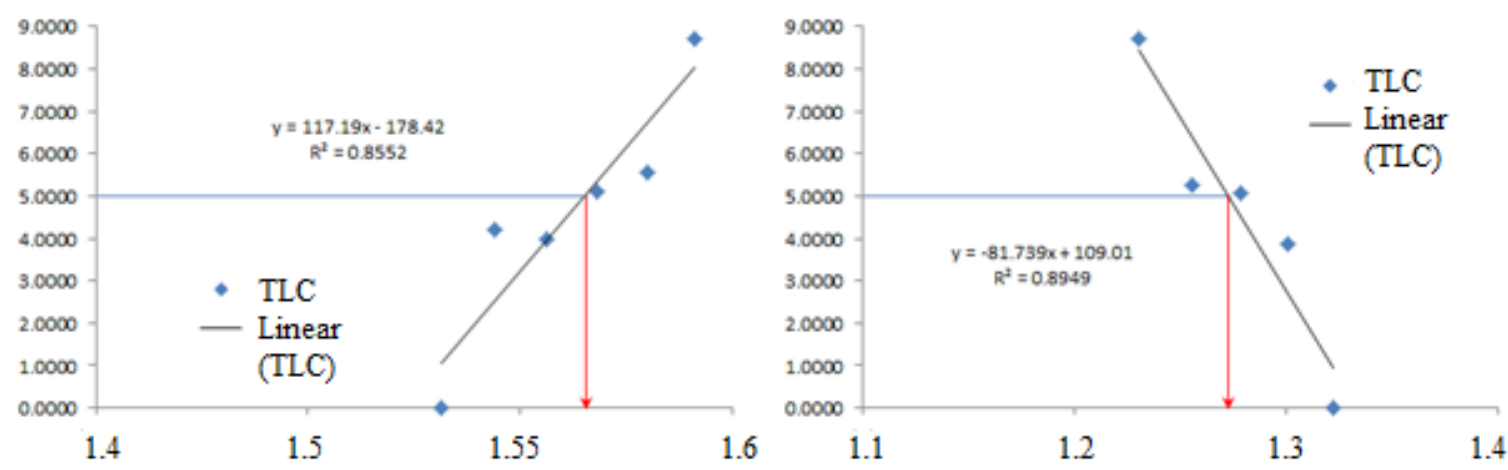

Hình 2. Phương trình hồi qui tuyến tính của tỷ lệ chết cá chốt bông giai đoạn mới nở theo nhiệt độ cao (trái) và thấp (phải).
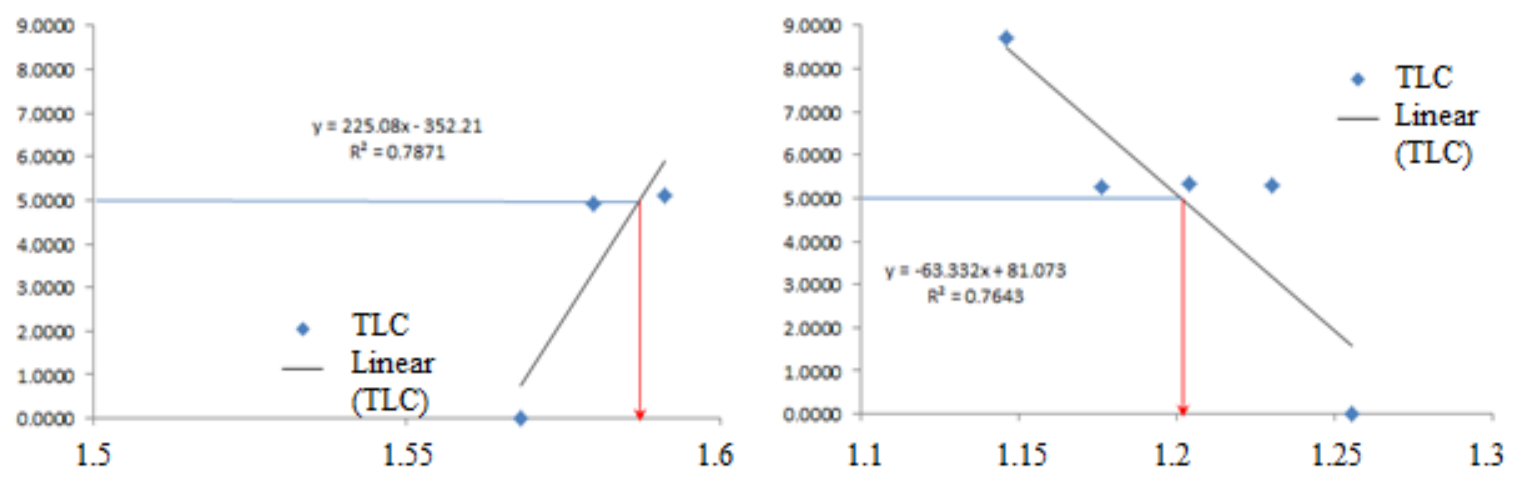

Hình 3. Phương trình hồi qui tuyến tính của tỷ lệ chết cá chốt bông giai đoạn 10 ngày tuổi theo nhiệt độ cao (trái) và thấp (phải).

phôi có hai thời kỳ nhạy cảm nhất với các yếu tố môi trường. Đó là thời kỳ phôi vị và thời kỳ phần đuôi tách khỏi noãn hoàng. Khi nhiệt độ 30 - $31^{0} \mathrm{C}$ tỉ lệ dị hình của phôi 60 - $70 \%$ và tỉ lệ phôi chết trước khi nở 50 - 60\% (Nguyen, 2005).
Theo Truong (2003), nhiệt độ thích hợp cho đa số các loài cá nuôi nước ngọt từ $25-32^{0} \mathrm{C}$, giới hạn nhiệt độ cho phép là $10-40^{\circ} \mathrm{C}$. Theo Fishbase (https://www.fishbase.se/summary/11987), cá chốt bông là loài cá sống ở vùng nhiệt đới, 
thích hợp phát triển ở nhiệt độ từ $20-26^{0} \mathrm{C}$.

Trong nghiên cứu này nhiệt độ cao gây chết (IULT) cá chốt bông giai đoạn 10 ngày tuổi $\left(38,6^{0} \mathrm{C}\right)$ là cao hơn giai đoạn mới nở $\left(36,7^{0} \mathrm{C}\right)$ và của giai đoạn mới nở là cao hơn giai đoạn phôi $\left(32,5^{0} \mathrm{C}\right)$. Ngược lại, nhiệt độ thấp gây chết (ILLT) cá chốt bông giai đoạn 10 ngày tuổi $\left(15,9^{0} \mathrm{C}\right)$ là thấp hơn giai đoạn mới nở $\left(18,7^{0} \mathrm{C}\right)$ và của giai đoạn mới nở thấp hơn giai đoạn phôi $\left(22,3^{0} \mathrm{C}\right)$. Điều này có thể kết luận rằng khả năng chịu đựng nhiệt độ bất lợi của cá chốt bông tăng dần theo sự phát triển và tuổi cá. Khi cơ thể cá ngày càng hoàn chỉnh thì chịu đựng điều kiện bất lợi của môi trường tốt hơn.

Nhìn chung, biên độ nhiệt độ gây chết cá chốt bông là hẹp hơn so với một số loài cá nuôi ở ĐBSCL. So với cá chép Cyprinus carpio và cá thác lác còm Chitala chitala thì nhiệt độ cao gây chêt cá chốt bông thấp hơn nhưng nhiệt độ thấp gây chết cao hơn. Ngưỡng nhiệt độ cao và thấp của cá chép lần lượt là $41,1^{0} \mathrm{C}$ và $4,5-9,2^{0} \mathrm{C}$ (Nguyen, 2004) và của cá thát lát còm là $41-41,7^{0} \mathrm{C}$ và $10,1-11^{0} \mathrm{C}$ (La, 2012). Nhiệt độ cao gây chết cá chốt bông cũng thấp hơn cá tra Pangasianodon hypophthalmus $\left(40,8^{\circ} \mathrm{C}\right)$ và cá basa Pangasius bocourti $\left(40,3^{\circ} \mathrm{C}\right)$ nhưng nhiệt độ thấp gây chết là tương đương cá tra $\left(16,7^{\circ} \mathrm{C}\right)$ ở giai đoạn giống (Duong, 2003). Sự khác biệt này có thể do sự khác nhau về phương pháp nghiên cứu cũng như khả năng chịu đựng của loài.

\subsection{Ngưỡng pH của cá chốt bông}

\subsubsection{Giai đoạn phôi}

- Ngưỡng pH cao gây chết (IULpH)

Phôi không chết ở các pH từ $7-9$. Hiện tượng phôi chết xảy ra ở các nghiệm thức có giá trị pH từ 10 - 11; trong đó, tỷ lệ phôi chết tích lũy ở 24 giờ ở $\mathrm{pH}=10$ là $21,3 \%$ và tăng lên $52,3 \%$ ở $\mathrm{pH}$ $=11$. Tỷ lệ phôi chết tích lũy ở 24 giờ ở $\mathrm{pH}=$ 10 và 11 là khác biệt có ý nghĩa thống kê $(P<$ $0,05)$ và cũng khác biệt so với tỷ lệ chết ở các $\mathrm{pH}$ khác.

Phương trình hồi qui tuyến tính của tỷ lệ phôi chết $(\mathrm{y})$ theo $\mathrm{pH}$ cao $(\mathrm{x})$ là $\mathrm{y}=58,627 \mathrm{x}-55,455$ $\left(\mathrm{R}^{2}=0,8911\right)$. Như vậy, trong thí nghiệm này, pH cao gây chết (IULpH) cá chốt bông giai đoạn phôi được xác định là 10,7 (Hình 4).

- Ngưỡng pH thấp gây chết (ILLpH)

Phôi không chết ở $\mathrm{pH}=7$. Hiện tượng phôi chết xảy ra ở các nghiệm thức có giá trị $\mathrm{pH}$ từ
6 - 3. Tỷ lệ phôi chết tích lũy ở 24 giờ ở nghiệm thức $\mathrm{pH}=6,7$ và 8 là tương đương nhau $(20,3$ $21,3 \%$ ), và tỷ lệ phôi chết là $100 \%$ sau 7 giờ thí nghiệm ở $\mathrm{pH}=3$. Tỷ lệ phôi chết tích lũy ở 24 giờ ở cá $\mathrm{pH}=6,7$ và 8 là khác biệt không có ý nghĩa thống kê $(P>0,05)$ nhưng khác biệt có ý nghĩa thống kê $(P<0,05)$ so với tỷ lệ chết ở các pH khác.

Phương trình hồi qui tuyến tính của tỷ lệ phôi chết $(\mathrm{y})$ theo $\mathrm{pH}$ thấp $(\mathrm{x})$ là $\mathrm{y}=-19,099 \mathrm{x}+$ $17,252\left(\mathrm{R}^{2}=0,81\right)$. Trong thí nghiệm này, $\mathrm{pH}$ thấp gây chết (ILLpH) cá chốt bông giai đoạn phôi được xác định là 4,4 (Hình 4).

\subsubsection{Giai đoạn cá mới nở}

\section{- Ngưỡng pH cao gây chết (IULpH)}

Kết quả cho thấy cá không chết ở các pH từ 7 - 9. Hiện tượng cá chết xảy ra ở các nghiệm thức có giá trị pH từ 10 - 11. Tỷ lệ cá chết tích lũy ở 24 giờ ở nghiệm thức $\mathrm{pH}=10$ là $38,0 \%$, tăng lên $55,3 \%$ ở $\mathrm{pH}=10,5 ;$ ở $\mathrm{pH}$ cao hơn $(\mathrm{pH}=11)$, tỷ lệ cá chết là $100 \%$ sau 1 giờ thí nghiệm. Tỷ lệ cá chết tích lũy ở 24 giờ ở $\mathrm{pH}=10$ và 10,5 là khác biệt có ý nghĩa thống kê $(P<0,05)$ và cũng khác biệt so với tỷ lệ chết ở các pH khác.

Phương trình hồi qui tuyến tính của tỷ lệ cá chết $(\mathrm{y})$ theo $\mathrm{pH}$ cao $(\mathrm{x})$ là $\mathrm{y}=93,58 \mathrm{x}-89,337$ $\left(\mathrm{R}^{2}=0,9617\right)$. Như vậy trong thí nghiệm này, $\mathrm{pH}$ cao gây chết (IULpH) cá chốt bông giai đoạn mới nở được xác định là 10,2 (Hình 5).

- Ngưỡng pH thấp gây chết (ILLpH)

Tương tự, cá không chết ở các pH từ $7-5$. Hiện tượng cá chết xảy ra ở các nghiệm thức có giá trị pH từ $4-3$. Tỷ lệ cá chết tích lũy ở 24 giờ ở nghiệm thức $\mathrm{pH}=4$ là $31,6 \%$, tăng lên $51,6 \%$ ở $\mathrm{pH}=3,5 ;$ ở $\mathrm{pH}$ thấp hơn $(\mathrm{pH}=3)$, tỷ lệ cá chết là $100 \%$ sau 2 giờ thí nghiệm. Tỷ lệ cá chết tích lũy ở 24 giờ ở $\mathrm{pH}=4$ và 3,5 là khác biệt có ý nghĩa thống kê $(P<0,05)$ và cũng khác biệt so với tỷ lệ chết ở các pH khác.

Phương trình hồi qui tuyến tính của tỷ lệ cá chết $(\mathrm{y})$ theo $\mathrm{pH}$ thấp $(\mathrm{x})$ là $\mathrm{y}=-37,282 \mathrm{x}+$ $26,214\left(\mathrm{R}^{2}=0,9617\right)$. Trong thí nghiệm này, $\mathrm{pH}$ thấp gây chết (ILLpH) cá chốt bông giai đoạn mới nở được xác định là 3,7 (Hình 5).

\subsubsection{Giai đoạn cá 10 ngày tuổi}

- Ngưỡng pH cao gây chết (IULpH)

Tương tự thí nghiệm trên, cá không chết ở các pH từ $7-9$. Hiện tượng cá chết xảy ra ở các 

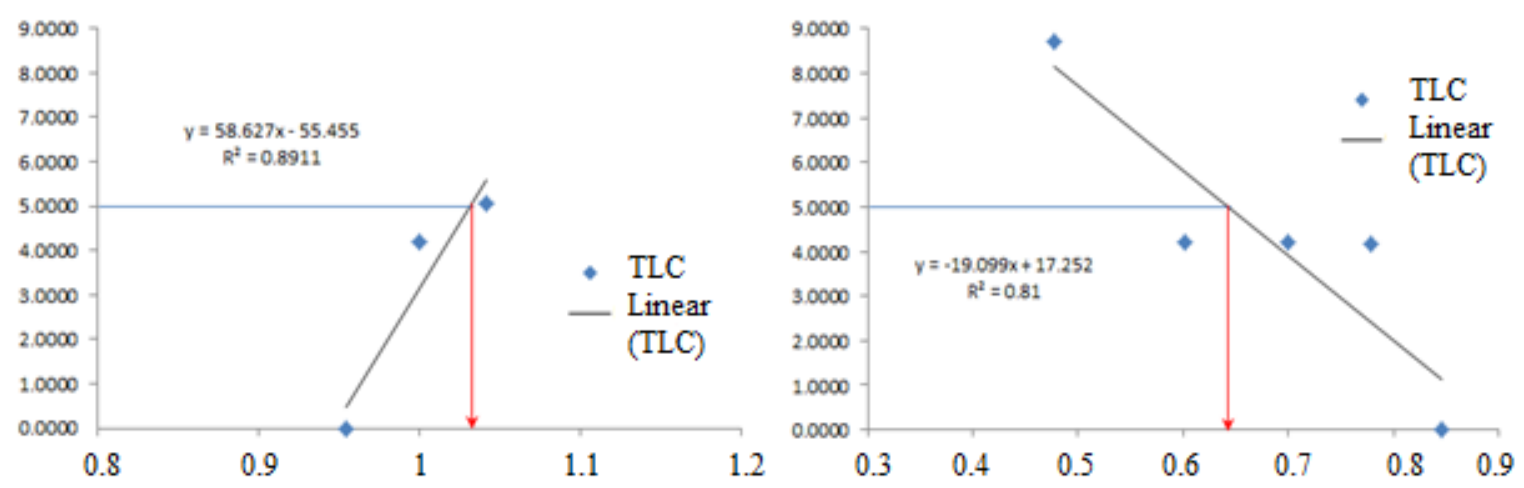

Hình 4. Phương trình hồi qui tuyến tính của tỷ lệ chết phôi cá chốt bông theo $\mathrm{pH}$ cao (trái) và thấp (phải).
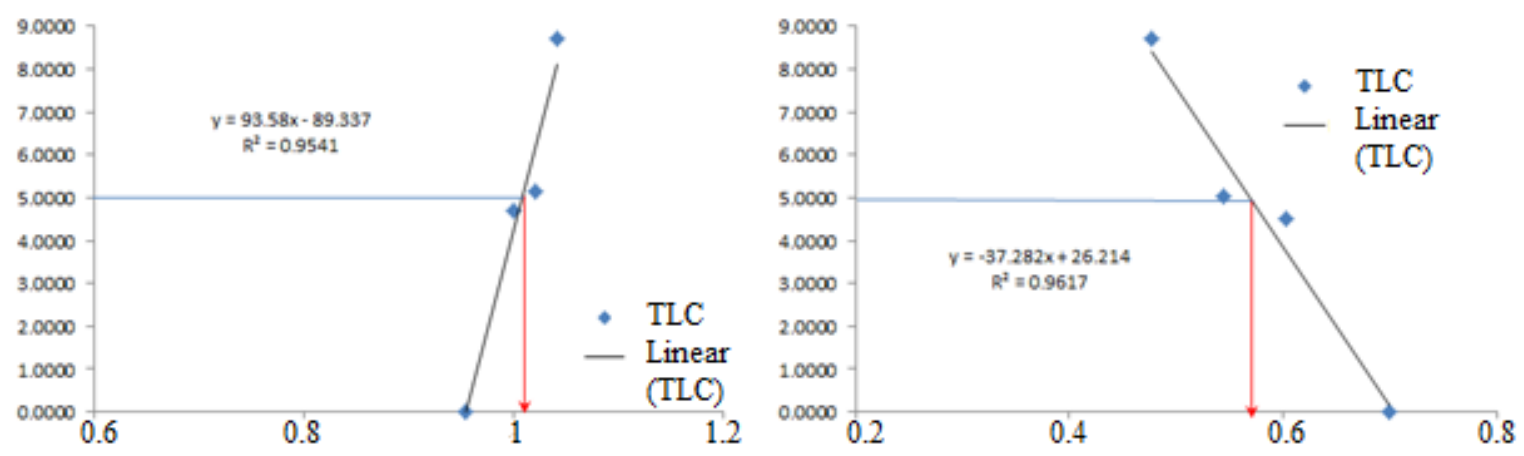

Hình 5. Phương trình hồi qui tuyến tính của tỷ lệ chết cá chốt bông giai đoạn mới nở theo pH cao (trái) và thấp (phải).
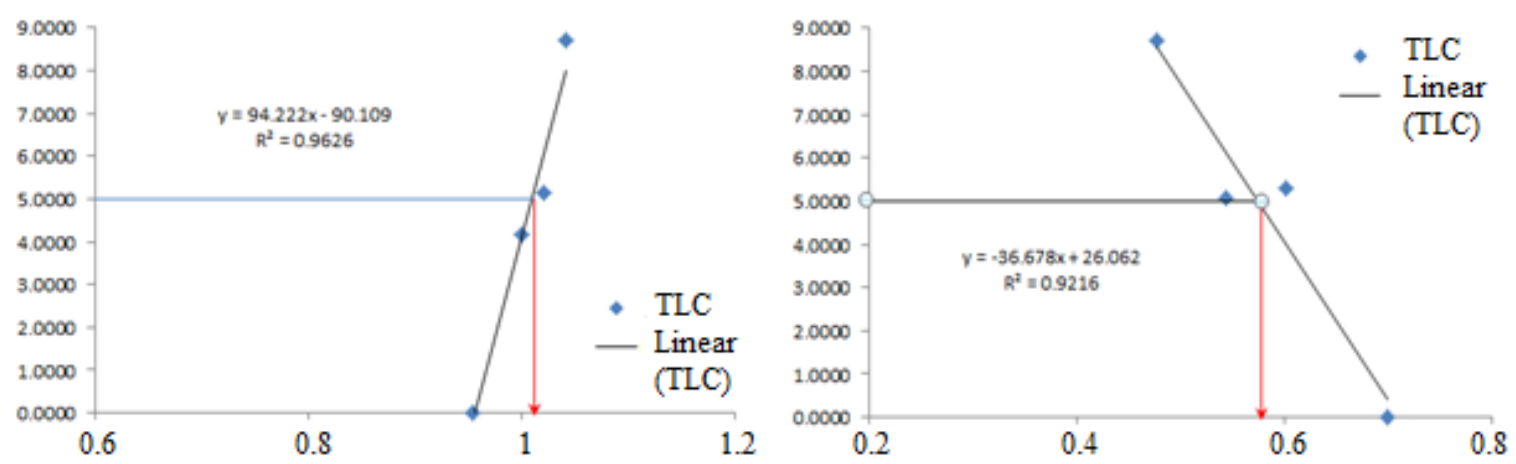

Hình 6. Phương trình hồi qui tuyến tính của tỷ lệ chết cá chốt bông giai đoạn 10 ngày tuổi theo pH cao (trái) và thấp (phải).

nghiệm thức có giá trị pH từ 10 - 11. Tỷ lệ cá chết tích lũy ở 24 giờ ở nghiệm thức $\mathrm{pH}=10$ là $20,0 \%$, tăng lên $56,3 \%$ ở $\mathrm{pH}=10,5$ và tỷ lệ cá chết là $100 \%$ sau 1 giờ thí nghiệm ở $\mathrm{pH}=11$. Tỷ lệ cá chết tích lũy ở 24 giờ ở $\mathrm{pH}=10$ và 10,5 là khác biệt có ý nghĩa thống kê $(P<0,05)$ và cũng khác biệt so với tỷ lệ chết ở các pH khác.

Phương trình hồi qui tuyến tính của tỷ lệ cá chết $(\mathrm{y})$ theo $\mathrm{pH}$ cao $(\mathrm{x})$ là $\mathrm{y}=94,222 \mathrm{x}-90,109$ $\left(\mathrm{R}^{2}=0,9626\right) \cdot \mathrm{pH}$ cao gây chết (IULpH) cá chốt bông giai đoạn 10 ngày tuổi được xác định là 10,2 (Hình 6). 
Bảng 1. Ngưỡng ôxy hòa tan $\left(\mathrm{mg} \mathrm{O}_{2} / \mathrm{L}\right)$ của cá chốt bông ở các giai đoạn phát triển khác

\begin{tabular}{cccc}
\hline Lần lặp lại & Giai đoạn phôi & Giai đoạn mới nở & Giai đoạn 10 ngày tuổi \\
\hline 1 & 4,8 & 0,9 & 1,2 \\
2 & 4,3 & 1,0 & 0,8 \\
3 & 5,2 & 1,3 & 1,0 \\
\hline Trung bình & $4,7 \pm 0,5$ & $1,1 \pm 0,2$ & $1,0 \pm 0,2$ \\
\hline
\end{tabular}

- Ngưỡng pH thấp gây chết (ILLpH)

Cá không chết ở các $\mathrm{pH}$ từ $7-5$. Hiện tượng cá chết xảy ra ở các nghiệm thức có giá trị $\mathrm{pH}$ từ 4 - 3. Tỷ lệ cá chết tích lũy ở 24 giờ của nghiệm thức $\mathrm{pH}=4$ là $61,6 \%$ và của $\mathrm{pH}=3,5$ là $52,3 \%$; tỷ lệ cá chết tích lũy của nghiệm thức $\mathrm{pH}=3$ là 100\% sau 2 giờ thí nghiệm. Tỷ lệ cá chết tích lũy ở 24 giờ ở $\mathrm{pH}=4$ và 3,5 là khác biệt có ý nghĩa thống kê $(P<0,05)$ và cũng khác biệt so với tỷ lệ chết ở các pH khác.

Phương trình hồi qui tuyến tính của tỷ lệ cá chết $(\mathrm{y})$ theo $\mathrm{pH}$ thấp $(\mathrm{x})$ là $\mathrm{y}=-36,678 \mathrm{x}+$ $26,062\left(\mathrm{R}^{2}=0,9216\right)$. pH thấp gây chết (ILLpH) cá chốt bông giai đoạn 10 ngày tuổi được xác định là 3,8 (Hình 6).

Theo Truong (2003), pH là một trong những yếu tố môi trường ảnh hưởng rất lớn đến đời sống cá. pH có ảnh hưởng trực tiếp đến các giai đoạn phát triển ban đầu của cá. Đa số các loài cá có thể chịu đựng một giới hạn rộng của $\mathrm{pH}$, từ 5 9. Trong nghiên cứu về ảnh hưởng của $\mathrm{pH}$ trên cá Prochilodus lineatus, Reynalte-Tataje \& ctv. (2015) đã tìm thấy ở pH 5,0 toàn bộ trứng bị chết sau 4 giờ. Trứng được ấp ở $\mathrm{pH}$ từ 6,0 - 8,5 có tỉ lệ thụ tinh và tỉ lệ sống tương tự nhau nhưng ở $\mathrm{pH}$ 6,0 trứng có đường kính nhỏ hơn và âu trùng cá có chiều dài ngắn hơn so với trứng được ấp ở môi trường trung tính hay kiềm. Trong giai đoạn ương nuôi ấu trùng, tỉ lệ sống của hậu ấu trùng cao nhất ở pH 7,0. Jellyman \& Harding (2014) nghiên cứu trên 5 loài cá nước ngọt ở New Zealand tìm thấy tất cả các loài cá bị chết khi $\mathrm{pH}$ nước $<4$ nhưng cá trưởng thành có thể sống ở $\mathrm{pH} 4,5$ và cá trưởng thành chịu đựng $\mathrm{pH}$ thấp tốt hơn cá con.

Kết quả các thí nghiệm trên cho thấy $\mathrm{pH}$ cao gây chết (IULpH) cá chốt bông giai đoạn 10 ngày tuổi $(10,2)$ là bằng giai đoạn mới nở $(10,2)$ và thấp hơn giai đoạn phôi $(10,7)$. Ngược lại, pH thấp gây chết (ILLpH) cá chốt bông giai đoạn 10 ngày tuổi $(3,8)$ là tương đương giai đoạn mới nở $(3,7)$ và thấp hơn giai đoạn phôi $(4,4)$. Điều này có thể kết luận rằng khả năng chịu đựng $\mathrm{pH}$ bất lợi của cá chốt bông sau nở là kém hơn phôi đối với $\mathrm{pH}$ cao và tốt hơn đối với $\mathrm{pH}$ thấp.

Nhìn chung, pH cao gây chết phôi cá chốt bông là thấp hơn so với phôi của cá rô đồng Anabas testudineus $(\mathrm{pH}=11)$ và cá sặc rằn Trichogaster pectoralis $(\mathrm{pH}=11,8)(\mathrm{Le}, 2010)$. $\mathrm{pH}$ cao gây chết cá chốt bông là tương đương với cá chép $(9,5$ 10,8) (Nguyen, 2004), cá tai tượng Osphronemus goramy (9,5 - 11) (Trang, 2010). pH thấp gây chết cá chốt bông là tương đương so với cá thát lát còm Notopterus chitala $(3,5-4,5)$ (La, 2012), thấp hơn so với cá chép $(4,2-4,5)$ (Nguyen, 2004) và cá tai tượng $(4,0-4,5)$ (Trang, 2010), và cao hơn so với cá sặc rằn(2,4) (Le, 2010). Sự khác biệt này cũng có thể do sự khác nhau về phương pháp nghiên cứu cũng như khả năng chịu đựng của loài.

\subsection{Ngưỡng ôxy hòa tan $(\mathrm{DO})$ của cá chốt bông}

Kết quả thí nghiệm xác định ngưỡng ôxy ở các giai đoạn phát triển khác nhau của cá chốt bông được trình bày ở Bảng 1 .

Theo Nguyen (2005), hàm lượng ôxy hòa tan trong nước thích hợp cho cá hoạt động sinh trưởng và phát triển, để đảm bảo cho phôi phát triển bình thường là $3-5 \mathrm{mg} / \mathrm{L}$. Trong hầu hết trường hợp, hàm lượng ôxy hòa tan trong nước thấp hơn $2 \mathrm{mg} / \mathrm{L}$ thì phôi sẽ chết ngạt. Giai đoạn còn nhỏ, cá con có ngưỡng ôxy cao, cao nhất đó là giai đoạn phôi tự do và cá bột (Pham \& Nguyen, 2009).

Ngưỡng ôxy của cá chốt bông là thấp hơn rất nhiều so với của phôi. Ngưỡng ôxy của cá chốt bông cao hơn so với cá chép $(0,22-0,11 \mathrm{mg}$ $\left.\mathrm{O}_{2} / \mathrm{L}\right)$, cá trắm cỏ Ctenopharyngodon idella $(0,49$ - 0,22 mg $\left.\mathrm{O}_{2} / \mathrm{L}\right)$, cá mè trắng Hypophthalmichthys harmandi $\left(0,89-0,55 \mathrm{mg} \mathrm{O}_{2} / \mathrm{L}\right)$ và cá trôi Labeo rohita $\left(0,97\right.$ - 0,66 mg $\mathrm{O}_{2} / \mathrm{L}$ ) (Nguyen, 2004; Tran, 2007). 


\section{Kết Luận và Kiến Nghị}

\subsection{Kết luận}

Ngưỡng nhiệt độ cao và thấp của phôi là $32,5^{0} \mathrm{C}$ và $22,3^{0} \mathrm{C}$; cá mới nở là $36,7^{0} \mathrm{C}$ và $18,7^{\circ} \mathrm{C}$; cá 10 ngày tuổi là $38,6^{\circ} \mathrm{C}$ và $15,9^{\circ} \mathrm{C}$. Ngưỡng $\mathrm{pH}$ cao và thấp ở giai đoạn phôi là 10,7 và 4,4 ; cá mới nở là 10,2 và 3,7 cá 10 ngày tuổi là 10,2 và 3,8 . Ngưỡng ôxy của cá chốt bông giai đoạn phôi, cá mới nở và cá 10 ngày tuổi lần lượt là 4,$7 ; 1,1 ; 1,0$ $\mathrm{mg} \mathrm{O}_{2} / \mathrm{L}$.

\subsection{Kiến Nghị}

Cần nghiên cứu ảnh hưởng của nhiệt độ, $\mathrm{pH}$ và ôxy hòa tan đến quá trình thành thục sinh dục và sinh sản của cá chốt bông.

Cần tiến hành thêm các nghiên cứu để xác định các ngưỡng của các yếu tố môi trường khác của cá chốt bông như độ mặn, ammonia, nitrite,...

\section{Tài Liệu Tham Khảo (References)}

Beitinger, T. L., Bennett, W. A., \& McCauley, R. W. (2000). Temperature tolerances of North American freshwater fishes exposed to dynamic changes in temperature. Environmental Biology of Fishes 58, 237275.

Duong, Y. T. (2003). Study on some morphological, growth and physiological characteristics of basa (Pangasius bocourti), tra (Pangasius hypophthalmus) and their hybrid. (Unpublished master's thesis). Can Tho University, Can Tho, Vietnam.

Jellyman, P. G., \& Harding, J. S. (2014). Variable survival across low $\mathrm{pH}$ gradients in freshwater fish species. Journal of Fish Biology 85, 1746-1752.

La, N. A. (2012). Study on some biological characteristics of knife fish (Chitala chitala) at embryonic, larval and fingerling stages. Can Tho University Journal of Science 21b, 62-67.

Le, K. P. (2010). Effects of salinity and $p H$ on the growth of embryo and larvae of climbing perch. (Unpublished master's thesis). Can Tho University, Can Tho, Vietnam.

Linder, R. S. (2000a). The catfishes of Asia family bagridae. (Part one). Cat Chat 1. Retrieved April 1, 2019, from https://www.planetcatfish.com/shanesworld/ shanesworld.php?article_id=185.
Linder, R. S. (2000b). The catfishes of Asia family bagridae. (Part one). Cat Chat 1. Retrieved April 1, 2019, from https://www.planetcatfish.com/shanesworld/ shanesworld.php?article_id=186.

Nguyen, K. V. (2004). Some morphological, ecological, biochemical and genetic characteristics of three common carp strains (yellow, white and Hungary) in Mekong river delta. (Unpublished doctoral dissertation). Nha Trang Fisheries University, Nha Trang, Vietnam.

Nguyen, K. V. (2005). Textbook on fish seed production. Can Tho University, Can Tho, Vietnam.

Nguyen, T. V. (2005). Lecture on physiology of fish and crustacean. Nong Lam University, Ho Chi Minh City, Vietnam.

Pham T. M., \& Nguyen K. V. (2009). Scientific basis and technique of fish seed production. Ho Chi Minh City, Vietnam: Agricultural Publishing House.

Reynalte-Tataje, D. A., Baldisserotto, B., \& ZaniboniFilho, E. (2015). The effect of water $\mathrm{pH}$ on the incubation and larviculture of curimbatá Prochilodus lineatus (Valenciennes, 1837) (Characiformes: Prochilodontidae). Neotropical Ichthyology 13(1), 179-186.

Tran, V. V. (2007). Textbook on Fisheries. Ha Noi, Vietnam: University of Education Publishing House.

Trang, P. V. (2010). Study on effects of salinity on growth and osmotic regulation of snake-skin gouramy (Trichogaster pectoralis Regan, 1910). (Unpublished master's thesis). Can Tho University, Can Tho, Vietnam.

Truong, P. Q. (2003). Water quality management of freshwater fish pond. Ho Chi Minh City, Vietnam: Agricultural Publishing House.

Vo, B. T. T. (2015). Study on some biological characteristics of Asian bumblebee catfish (Pseudomystus siamensis Regan, 1913). Report of scientific research. Nong Lam University, Ho Chi Minh City, Vietnam.

Wokoma, K., \& Marioghae, I. E. (1996). Survival of Tilapia guineensis under conditions of low dissolved oxygen and low pH. In Pullin, R. S. V., Lazard, J., Legendre, M., Amon Kothlas, J. B., \& Pauly, D. (Eds.). ICLARM Conferenc 41: The Third International Symposium on Tilapia in Aquaculture (442448). Makati City, Philippines. 